\title{
A consciência textual no gênero fábula: proposta e análise de um instrumento de verificação da coerência com alunos do Ensino Fundamental
}

\author{
The textual awareness in the fable genre: proposal and analysis of \\ a coherence verification tool with students of Elementary Education
}

\section{Patricia de Andrade Neves \\ Caroline Bernardes Borges}

Pontifícia Universidade Católica do Rio Grande do Sul - PUCRS - Rio Grande do Sul - Brasil

\begin{abstract}
Resumo: Os resultados das provas nacionais oficiais mostram que cada vez mais os alunos têm dificuldade na compreensão de textos. Dentre as possíveis razões, há o elevado índice de analfabetismo entre os alunos dos anos iniciais e o desempenho apenas básico de leitura entre os alfabetizados. Tendo como ponto de partida esse cenário educacional, o propósito deste artigo é a apresentação e a análise de um instrumento de verificação da consciência textual (GOMBERT, 1992), no que se refere à coerência (CHAROLLES, 1978), utilizando a fábula, um gênero textual de estrutura predominantemente narrativa (ADAM, 2011), que possa ser aplicado em alunos do 6o ano do Ensino Fundamental. Com esse objetivo, após a apresentação do instrumento de verificação, cada questão é analisada sob o viés dos estudos citados, de modo a contribuir com uma ferramenta para os professores que favorece o conhecimento da situação de consciência textual de seus alunos.
\end{abstract}

Palavras-chave: Coerência. Consciência Textual. Instrumento de Verificação.

Abstract: The results of the official national exams show that increasingly the students have difficulty in reading and understanding texts. Among the possible reasons, there are the high illiteracy rate between the elementary students and the only basic reading performance among literates. Starting from this educational scene, the purpose of this paper is the presentation and the analysis of a textual awareness verification tool (GOMBERT, 1992), as regards coherence (CHAROLLES, 1978), using the fable, a textual genre of predominantly narrative structure (ADAM, 2011), that can be applied to students of the 6th year of Elementary Education. To this end, after the presentation of the verification tool, each question is analyzed under the bias of the studies cited above, in order to contribute with a tool to the teachers that improves the knowledge of the textual awareness situation of their students.

Keywords: Coherence. Textual Awareness. Verification Tool 


\section{Introdução}

Nas aulas de Língua Portuguesa na educação básica, o letramento torna-se uma das metas mais difíceis, pois espera-se que um aluno letrado leia e compreenda um texto detendo-se também nas inferências. A leitura é "uma tarefa complexa que depende de processos perceptivos, cognitivos e linguísticos" (COLOMER; CAMPS, 2002, p.32). Sendo assim, a competência sintática, semântica e textual são necessárias na formação do leitor.

As Neurociências também propiciaram grandes descobertas sobre a leitura. Uma delas diz respeito às partes cerebrais e suas funções no ato de ler. Por exemplo, na região occipital ocorre o processamento dos sinais luminosos que são captados pela região central da retina, e na região occípito-temporal ventral esquerda ocorre o reconhecimento da palavra escrita (DEHAENE, 2009). O cérebro, por sua vez, decodifica ativamente a identificação das letras e das palavras, acrescentando a informação ao sinal visual. Nessa perspectiva, todas as pessoas ativam a mesma região cerebral no ato da leitura, todas leem com a mesma área cerebral. A cultura evolui para ser apreendida pelo cérebro e, dentre as evoluções culturais, o ato de ler foi uma dessas aprendizagens (DEHAENE, 2012).

Segundo Flôres (2008), há a distinção entre o leitor que apenas decifra o que está escrito, utilizando a lógica interna do texto, e aquele leitor que lê fazendo uma leitura crítica que envolva as inferências. Pereira (2014) afirma que frequentemente são os aspectos temáticos, em detrimento dos aspectos linguísticos, que são mais trabalhados no ensino da leitura e da escrita.

O trabalho com os tópicos linguísticos advindos da Psicolinguística, como, por exemplo, a consciência textual (GOMBERT, 1992) com foco na coerência (CHAROLLES, 1978), pode auxiliar o aluno na interpretação de um texto específico. Segundo Adam (2011), compreender um texto é além de ler uma sequência após a outra, é também ter noção do todo enunciativo. Sendo assim, o leitor precisa ir além do que está explícito, não apenas decodificar os textos, pois o que está subentendido e implícito faz-se importante na compreensão textual.

Dessa forma, o presente artigo propõe a apresentação de um instrumento de verificação da consciência textual com foco na coerência, através do gênero fábula e do tipo textual narrativo, que sirva como uma ferramenta para os professores no conhecimento da situação de consciência textual de seus alunos. Além disso, também é objetivo do estudo apresentar a análise desse instrumento de verificação sob o viés dos fundamentos teóricos apresentados. O público-alvo desse instrumento são alunos do $6^{\circ}$ ano do Ensino Fundamental, alunos esses que acabaram de terminar os anos iniciais e, portanto, são alfabetizados e estão no processo de letramento.

\section{Gênero fábula e tipo textual narrativo}

Marcuschi (2003) faz a distinção entre tipo textual e gênero textual: para o autor (2003), a expressão tipo textual designa uma série de constructos teóricos definidos por certas propriedades linguísticas, constituindo uma determinada sequência de enunciados dominantes e um conjunto de aspectos lexicais de relações lógicas e de tempo verbal. Já a expressão gênero textual se refere a textos que fazem parte do nosso cotidiano de forma materializada e que apresentam características relacionadas ao conteúdo, às propriedades funcionais, ao estilo e à composição característica, como por exemplo: crônica, fábula, música e textos não verbais.

Squire (2005) afirma que o tipo textual narrativo é composto por um conjunto de signos que podem se mover de forma temporal e que podem operar inclusive em imagens (texto não verbal). Todos os textos narrativos possuem uma estrutura hierárquica, segundo Adam (2011), com número certo de sequências. Para que o texto obtenha um alto grau de narrativização a trama deve ser constituída por cinco proposições essenciais: Pn1 - situação inicial (antecede o processo), Pn2 - nó (parte inicial do processo), Pn3 - avaliação (o percurso do processo), 
Pn4 - desenlace (final do processo) e Pn5 - situação final (após o processo). Se não houver essas cinco proposições na narrativa, essa é considerada com baixo grau de narrativização, resultando em apenas enumerações de ações. Duas proposições, segundo o autor (2011), são opcionais: Pn0 - abertura do texto (resumo ou prefácio) e $\mathrm{Pn} \Omega$ - encerramento do texto. Ademais, a narrativa envolve elementos como: narrador, enredo, espaço, tempo e personagens. Dessa forma, os estudos das sequências narrativas dominantes podem auxiliar o aluno no processo de compreensão leitora em textos narrativos. Esse tipo textual necessita da ordem cronológica e lógica para ser coerente; além disso, deve haver uma mudança do estado inicial para o final, juntamente com o clímax da narrativa, resultando na conclusão do texto:

Vimos que o reagrupamento de proposições narrativas em tríades imbricadas constitui grupos de funções. São estes grupos de proposições organizadas em ciclos que formam as sequências narrativas. Para que um grupo de proposições narrativas forme uma sequência é preciso não somente que um mesmo ator as unifique atravessando-as, mas também que haja uma transformação (ADAM, 1985, p.54).

Através desses estudos, podemos observar que a escola opta por trabalhar com textos que sejam narrativos nas séries iniciais do Ensino Fundamental, já que o tipo textual narrativo possui uma estrutura que se aproxima da experiência da criança com a linguagem. Segundo Cardoso (2000), desde o nascimento, a criança está interagindo com a narrativa através da contação de histórias e da reprodução do seu próprio discurso narrativo oral.

O gênero textual fábula possui o tipo textual narrativo, sendo um dos gêneros mais trabalhados durante os anos iniciais do Ensino Fundamental, pois 0 ato de narrar histórias está muito atrelado à infância, através de contos de fada e de narrativas infantis de um modo geral. Portanto, espera-se que os alunos do $6^{\circ}$ ano estejam familiarizados com esse gênero, lançando mão, dessa forma, de um amplo conhecimento prévio. Segundo Rojo (2000), a fábula possui as seguintes características: narrador onisciente (esclarecendo fatos e relações); moral no final da história, que possui um viés educativo e reflexivo (sendo esse um grande atrativo nesse gênero textual); narrativa breve; natureza simbólica (proporcionando uma fácil assimilação pelos leitores); estímulo à distração e à reflexão; personagens são geralmente animais, cujas atitudes são comparadas às dos seres humanos.

\section{A consciência textual e a coerência textual}

Dehaene (2009) relata que há uma diferença cerebral, a partir do tempo de 270-300 milissegundos, entre $o$ processamento consciente e $\mathrm{o}$ inconsciente. Isso acontece por meio da sincronia de diferentes áreas do cérebro. Sendo assim, a consciência (e, por sua vez, a consciência metalinguística), a partir de um tempo de trabalho, é realizada pela sincronia entre muitas regiões cerebrais e não apenas por uma área do cérebro.

Gombert (1992) afirma que a consciência metalinguística é um importante aspecto da compreensão leitora, pois através dela há a reflexão sobre os aspectos primários das atividades linguísticas. Essa encontra-se subdividida em: consciência fonológica (habilidade de segmentar, analisar e manipular intencionalmente sons que compõem a fala); consciência morfológica (habilidade de refletir sobre os morfemas); consciência sintática (habilidade de refletir e manipular a estrutura gramatical e os elementos linguísticos das sentenças); consciência pragmática (habilidade de refletir sobre o uso da língua) e consciência textual (habilidade de refletir a respeito do texto). Spinillo et al. (2010) relatam que a consciência linguística, ao ter vínculo com a compreensão leitora, trata do conhecimento da própria linguagem e está associada de forma predominante à memória declarativa e ao manejo dos elementos linguísticos.

Spinillo e Simões (2003) elucidam que a consciência textual, aquela focalizada pelo instrumento de verificação, volta a atenção do leitor para o texto de forma consciente e focaliza o texto como objeto de análise. Esse tipo de consciência considera aspectos como a estrutura (elementos que 
categorizam o texto como tal), a coerência (conteúdo do texto relacionado com a semântica e a pragmática), a coesão (elementos de ligação entre as frases e parágrafos) e a consciência procedimental (os procedimentos que o leitor se utiliza para compreender o texto). Outros fenômenos da língua também fazem parte da consciência textual, como por exemplo: a capacidade de monitoramento da leitura, os comportamentos metalinguísticos (o indivíduo julga de forma consciente e correta além de explicitar verbalmente quais critérios utilizou), a escrita de textos, a revisão e a manipulação de partes do texto (PEREIRA \& SCLIAR-CABRAL, 2012).

Dentre os aspectos que compõem a consciência textual, o presente artigo aborda no instrumento de verificação a metacompreensão (verbalização e ou escrita consciente dos critérios utilizados em determinadas atividades do instrumento) e a coerência textual. A compreensão leitora, segundo Guterman (2003), depende da metacompreensão, ou seja, do autoconhecimento do aluno para monitorar a própria compreensão e identificar quando não compreendeu o conteúdo lido. Dessa forma, o aluno durante a leitura faz uso de estratégias, as quais podem ser classificadas como cognitivas (operações inconscientes, ações realizadas pelo leitor, sem estar ciente disso, para atingir algum objetivo de leitura) e metacognitivas (operações controladas conscientemente, realizadas com algum objetivo em mente).

De acordo com Gombert (1992), um texto coerente possui ideias conectadas e a monitoração da coerência ocorre ao se detectarem contradições através de novas informações que o sujeito possui ou entre informações que estão de forma explícita ou implícita no texto. Sendo assim, faz-se necessário comparar os dados extralinguísticos com o que é fornecido pela mensagem do texto. Dessa forma, um dos aspectos textuais relevantes para que haja a compreensão leitora é a coerência, visto que ela é a responsável pelo sentido do texto, tratando-se de uma propriedade ideativa textual (SIMON, 2008).

Ferreira e Dias (2004) afirmam que o leitor interpreta e atribui coerência ao texto através do processo inferencial, pois os sentidos são produzidos através da interação entre o leitor e o texto. Esses sentidos são organizados e relacionados com as partes textuais e o contexto. Conforme Koch e Travaglia (2003), a coerência é algo que se estabelece na interação, na interlocução e na situação comunicativa entre os usuários.

Segundo Charolles (1978), a coerência se refere, predominantemente, ao conteúdo do texto e suas relações internas, bem como do texto com o seu entorno. Realiza-se por meio de quatro metarregras: metarregra de manutenção temática (para que haja coerência é necessário que ocorra repetição, lançando mão de recursos como pronominalizações, definitivações, referenciações contextuais, substituições lexicais, recuperações pressuposicionais e retomadas de inferência, ou seja, o texto deve girar em torno de um eixo temático); metarregra de progressão temática (mesmo com o tema devendo ser mantido, o texto deve progredir, avançar, se desenvolver, evitando que seja repetitivo); metarregra de não contradição ou ausência de contradição interna (não se pode introduzir uma nova informação ao desenvolvimento que seja contraditória à informação anterior, não ocorrendo dessa forma contradições temáticas ou linguísticas) e metarregra de relação com o mundo (os fatos, as ações, os eventos ou estados devem possuir vínculo com a realidade em textos não ficcionais e verossimilhança em textos ficcionais). $O$ instrumento de verificação explora as quatro metarregras, elucidadas por Charolles (1978), na verificação da coerência e, por conseguinte, da consciência textual no gênero fábula de tipo textual narrativo dominante.

\section{Metodologia}

O texto narrativo escolhido foi a fábula, justificado por ser um dos gêneros mais trabalhados durante os anos iniciais do Ensino Fundamental; dessa forma, espera-se um conhecimento prévio desse gênero textual por parte dos alunos. Foi escolhida a fábula "O Leão e o Rato", de Jean de La 
Fontaine, e, com base nesse texto, foram criadas nove atividades, formando um instrumento de verificação da consciência textual no aspecto da coerência, destinadas a estudantes do $6^{\circ}$ ano do Ensino Fundamental. As atividades contemplam os seguintes tópicos linguísticos: as quatro metarregras da coerência propostas por Charolles (1978), além de um protocolo verbal escrito e oral para verificar a metacompreensão ao final de cada questão.

Existem três tipos de protocolos verbais: autorelatório, auto-observação e auto-revelação (COHEN, 1987). De acordo com Tomich (2007), no autorelatório e na auto-observação as respostas são obtidas depois a leitura e, na auto-revelação, as respostas são obtidas durante o processo da leitura. De acordo com Leitão (2011), quando o procedimento ocorre durante a leitura, trata-se de um protocolo online, ao passo que, quando ocorre após a leitura, é chamado protocolo offline. O protocolo verbal utilizado no instrumento de verificação é do tipo autorelatório, pois refere-se à situação em que o leitor narra e descreve seu comportamento, no que se refere à leitura de textos, após a leitura e a realização da atividade, revelando possivelmente como ele acredita que age durante uma situação qualquer de leitura. Na proposta de instrumento aqui apresentada, o aluno deve descrever seu comportamento a partir de uma pergunta direcionada, após a realização de cada atividade. Já os dados do protocolo verbal oral serão obtidos por meio de gravação da voz e posterior transcrição dessas respostas por parte do professor aplicador.

Os alunos serão chamados individualmente para responder 0 instrumento. Inicialmente 0 aluno responde à questão, em seguida realiza o protocolo verbal oral da questão (que será gravado e posteriormente transcrito pelo professor aplicador) e, por fim, é solicitado ao aluno o protocolo verbal escrito da mesma questão. Nessa perspectiva, têmse os dados do protocolo verbal tanto orais quanto escritos e podem-se observar as diferenças e semelhanças nas duas maneiras de verificação da metacompreensão ao final de cada questão.
A escolha pelo auto-relatório se deu pelo fato de as respostas serem obtidas após a realização da leitura e da atividade, permitindo que $o$ aluno as conclua com atenção. Acredita-se que o modelo online, realizado por meio do protocolo referente à auto-revelação, pode atrapalhar o processo de leitura do aluno, bem como a resolução da atividade. Pelo fato do público-alvo ser alunos de $6^{\circ}$ ano do Ensino Fundamental, essa interrupção pode interferir negativamente. Além disso, qualquer tipo de protocolo exige introspecção e reflexão, e essas pausas para direcionar a atenção para 0 processo durante sua realização interrompem o fluxo de pensamento, o que também pode causar impactos negativos na realização da leitura e da atividade, considerando tal faixa etária.

Apesar dessas convicções, é importante ressaltar que se entende os limites de qualquer protocolo verbal, já que as explicações dadas pelos alunos podem não corresponder exatamente ao comportamento realizado durante a leitura. Trata-se de algo que pode ocorrer tanto no protocolo online como no protocolo offline e que não pode ser totalmente controlado em nenhuma situação. Em função disso, inclusive, que se sugere o protocolo escrito e oral, para que as explicações dos alunos possam ser exploradas o máximo possível, visto que a fala tende a ser mais espontânea do que a escrita.

Conforme salientado nos objetivos do estudo, pretende-se apresentar o instrumento de verificação elaborado e analisá-lo à luz da teoria, levando em consideração o contexto das aulas de leitura. Tratase, portanto, de atividades pedagógicas que podem ser utilizadas como ferramenta pelos professores, a fim de que eles possam mensurar o nível de compreensão e de consciência textual de seus alunos na própria sala de aula. Caso o instrumento venha a integrar um estudo aplicado futuramente, o que é possível, a pesquisa será submetida ao Comitê de Ética, dependendo de sua aprovação para o início à coleta dos dados.

As nove questões que compõem o instrumento de verificação estão assim organizadas: a primeira, a segunda e a terceira abordam a 
manutenção temática; a quarta e a quinta, a progressão temática; a sexta e a sétima, a ausência de contradição interna; e a oitava e a nona, a relação com o mundo real. Tendo em vista esses aspectos, será, primeiramente, realizada a análise do texto selecionado, com base nos pressupostos teóricos apresentados anteriormente. Após, serão propostas as nove questões referentes à fábula selecionada e, por fim, será apresentada a análise das questões, fazendo uma descrição de como essas questões pretendem, no formato de um instrumento de verificação, auxiliar o professor na verificação e análise do nível de consciência textual de seus alunos do 6ำ ano do Ensino Fundamental no aspecto da coerência.

\subsection{Análise do texto}

A progressão temática se caracteriza pela ordenação temporal. Ao identificar as partes que compõem uma narrativa, conforme observamos, há o auxílio na construção da coerência textual. A partir das cinco proposições narrativas de Adam (2011), a fábula "O Leão e o Rato" 1está organizada da seguinte forma:

Pn1 Certo dia estava um Leão a dormir a sesta quando um ratinho começou a correr por cima dele.

O Leão acordou, pôs-lhe a pata em cima, abriu a bocarra e preparouse para engoli-lo.

- Perdoa-me! - gritou o ratinho - Perdoa-me desta vez e eu nunca o esquecerei. Quem sabe se um dia não precisarás de mim?

O Leão ficou tão divertido com esta ideia que levantou a pata e o deixou partir

Pn2 Dias depois o Leão caiu numa armadilha. Como os caçadores o queriam oferecer vivo ao Rei, amarraram-no a uma árvore e partiram à procura de um meio para o transportarem.

Pn3 Nisto, apareceu o ratinho

Pn4 Vendo a triste situação em que o Leão se encontrava, roeu as cordas que o prendiam.

Pn5 E foi assim que um ratinho pequenino saltou o Rei dos Animais.

$\mathrm{Pn} \Omega$ Moral da história: Não devemos subestimar os outros.

LA FOUNTAINE, Jean de. Disponível em: <http://pensador.uol.com.br/frase/ODEwNDAw/>. Acesso em: 26/11/2017.
A fábula apresenta as cinco proposições narrativas de Adam (2011). De forma resumida, a situação inicial (Pn1) refere-se ao momento em que o leão captura o ratinho, mas o liberta; o nó (Pn2), a quando o leão cai em uma armadilha; a reação (Pn3), ao aparecimento do ratinho; o desenlace (Pn4), a quando o ratinho rói as cordas que prendem o leão; a situação final (Pn5), à conclusão de que o ratinho acaba salvando o Rei dos Animais; e, por fim, $\operatorname{Pn} \Omega$, referente à moral da história, a qual configura um encerramento que não se insere diretamente na narrativa, mas que agrega uma avaliação final ao fato narrado.

\subsection{Instrumento de verificação da coerência}

Nesta subseção, será mostrado o instrumento de verificação da coerência para a contemplação dos tópicos linguísticos citados anteriormente:

- Agora você vai ler uma fábula do Jean de La Fontaine; leia com atenção:

Certo dia estava um leão a dormir a sesta, definição de sesta: breve cochilada após o almoço; repouso após o almoço, geralmente no início da tarde; quando um ratinho começou a correr por cima dele. O leão, grande mamífero carnívoro da família dos felídeos, dotado de ampla juba (o macho), adstrito atualmente às savanas da África, depois de ter existido no Oriente Próximo e até na Europa, acordou, pôs-lhe a pata em cima, abriu a bocarra e preparou-se para engoli-lo. Processo que conduz alimentos, saliva e líquidos, da boca ao estômago, passando pela faringe e pelo esôfago.

- Perdoa-me! - gritou o ratinho - Perdoa-me desta vez e eu nunca o esquecerei. Quem sabe se um dia não precisarás de mim?

O leão ficou tão divertido com esta ideia que levantou a pata e o deixou partir.

Dias depois o leão caiu numa armadilha. Como os caçadores o queriam oferecer vivo ao Rei, amarraram-no a uma árvore e partiram à procura de um meio para o transportarem. 
Nisto, apareceu o ratinho. Vendo a triste situação em que o leão se encontrava, roeu as cordas que o prendiam.

$E$ foi assim que um ratinho pequenino salvou 0 Rei dos Animais.

- Agora que você leu a fábula, responda à questão 1:

1- Há três frases nessa fábula que não fazem parte do texto, sublinhe-as no texto.

Porque você sublinhou essas três frases? Como pensou para responder? Justifique.

- Agora você vai ler novamente a mesma fábula do Jean de La Fontaine; leia mais uma vez com atenção:

Certo dia estava um leão a dormir a sesta quando um ratinho começou a correr por cima dele. $O$ leão acordou, pôs-lhe a pata em cima, abriu a bocarra e preparou-se para engoli-lo.

- Perdoa-me! - gritou o ratinho - Perdoa-me desta vez e eu nunca o esquecerei. Quem sabe se um dia não precisarás de mim?

O leão ficou tão divertido com esta ideia que levantou a pata e o deixou partir.

Dias depois o leão caiu numa armadilha. Como os caçadores o queriam oferecer vivo ao Rei, amarraram-no a uma árvore e partiram à procura de um meio para o transportarem.

Nisto, apareceu o ratinho. Vendo a triste situação em que o leão se encontrava, roeu as cordas que o prendiam.

$E$ foi assim que um ratinho pequenino salvou o Rei dos Animais.

- Agora que você releu a fábula, responda às questões de 2 a 9 :
2- Marque a alternativa que contém o título mais adequado para a fábula:
a) $O$ rato e as cordas
b) O leão e o rato
c) O leão e o rei
d) O leão e os caçadores

Por que você escolheu essa alternativa? Como pensou para responder? Justifique.

3- Marque a alternativa que contém a moral mais adequada para a fábula:
a) Quem ama o feio, bonito lhe parece.
b) Não devemos subestimar os outros.
c) Falar é fácil, fazer é que é difícil.
d) Cuidado com quem muito elogia.

Por que você escolheu essa alternativa? Como pensou para responder? Justifique.

4- Numere os fatos da história em ordem cronológica:

( ) O leão caiu em uma armadilha feita pelos caçadores.

( ) O leão estava dormindo.

( ) O ratinho salvou o leão.

( ) O leão ia comer o ratinho, mas o deixou escapar.

( ) O ratinho passou por cima do leão e o acordou.

Por que você escolheu essa ordem? Como pensou para responder? Justifique.

5- Leia o seguinte trecho da fábula: "Dias depois o Leão caiu numa armadilha. Como os caçadores o queriam oferecer vivo ao Rei, amarraram-no a uma árvore e partiram à procura de um meio para o transportarem". A partir desse trecho, elabore um novo desfecho para a história:

Por que você escolheu esse desfecho? Como pensou para elaborá-lo? Justifique. 
6- Indique a alternativa que causa contradição com a história da fábula O Leão e o Rato:

a) O leão acordou e deixou o ratinho escapar.

b) O leão estava dormindo após o almoço e um ratinho o acordou.

c) O leão salvou o ratinho que estava em apuros.

d) O ratinho salvou o leão e sobreviveu.

Por que você escolheu essa alternativa? Como pensou para responder? Justifique.

7- Indique a alternativa que está contradizendo o desfecho da história:

a) $E$ foi assim que um ratinho pequenino ajudou o Rei dos Animais.

b) $E$ foi assim que um pequeno ratinho salvou o Rei dos Animais.

c) $E$ foi assim que um pequeno rato salvou $o$ Rei dos Animais.

d) $E$ foi assim que um ratinho pequenino deixou de salvar o Rei dos Animais.

Por que você escolheu essa alternativa? Como pensou para responder? Justifique.

8- Se no trecho "Como os caçadores o queriam oferecer vivo ao Rei, amarraram-no a uma árvore e partiram à procura de um meio para o transportarem. " houvesse a troca da palavra "árvore" pela palavra "flor", seria aceitável? Justifique.

Como você pensou para responder à questão oito? Justifique.

9- Seguem alguns trechos da história que foram alterados. Assinale o que não é aceitável.

a) O Leão ficou tão divertido com esta ideia que ergueu a pata e o deixou partir.

b) Vendo a triste situação em que o Leão se encontrava, o ratinho roeu as cordas que 0 mantinham preso.

c) Certo dia estava um Leão a dormir após o almoço, quando um ratinho começou a correr por cima dele.

d) Dias depois o Leão caiu numa nuvem.
Por que você escolheu essa alternativa? Como pensou para responder? Justifique.

\subsection{Análise do instrumento de verificação}

Nesta subseção serão analisadas as nove questões que contemplam os tópicos linguísticos citados anteriormente.

\subsubsection{Questão 1}

Inicialmente o aluno recebe a fábula "O leão e - Rato", com algumas alterações, e a primeira questão que se refere à manutenção temática. Sendo assim, o aluno deve localizar três frases que não fazem parte da fábula. Essas frases fazem parte de um tipo textual expositivo e de um gênero científico. Dessa forma, à medida que o aluno identifica essas três frases, ele consegue perceber que elas não fazem parte do eixo temático específico da fábula apresentada. Como destaca Charolles (1978), a manutenção do tema é uma das metarregras que garantem o estabelecimento da coerência do texto e, portanto, deve ser utilizada. Ao responder ao protocolo verbal oral e escrito do tipo auto-relatório, que está presente ao final de todas as questões, para verificar a metacompreensão do leitor, esse entendimento deve ficar explicitado. Trata-se de um método eficaz para desenvolver a compreensão leitora dos alunos, conforme destaca Gombert (1992), já que a consciência linguística (aqui, especificamente, a consciência textual), está relacionada diretamente à compreensão.

\subsubsection{Questão 2}

Posteriormente, o aluno recebe a fábula original "O leão e o Rato", sem nenhuma alteração, e as demais questões do instrumento. A segunda questão também diz respeito à manutenção temática textual, aspecto referente à coerência do texto. $O$ aluno deve escolher a alternativa, entre quatro opções, que contém o título mais adequado para a fábula. Através da escolha do título adequado, o 
aluno consegue perceber qual é o eixo temático da fábula, pois o título não deixa de ser uma sumarização da "unidade temática" do texto. A partir dessa seleção adequada e do descarte das demais opções (menos adequadas/inadequadas), o aluno precisa pensar sobre o tema do texto e, então, identificar o que está relacionado a ele ou não, exercitando a observação do aspecto da coerência textual proposto por Charolles (1978). Ao final dessa questão, os alunos também precisam explicar como pensaram para realizá-la, de forma oral e escrita, exercitando, também, a consciência textual e a metacompreensão.

\subsubsection{Questão 3}

A terceira questão também diz respeito à manutenção temática textual. $\mathrm{O}$ aluno deve escolher a alternativa, entre quatro opções, que contém a moral mais adequada para a fábula. Através da escolha da moral adequada e do descarte das morais inadequadas, o aluno consegue perceber qual é o eixo temático da fábula, pois a moral também consiste numa sumarização da "unidade temática" do texto. Para isso, ele precisa entender o que está relacionado ao tema do texto ou não, entendendo que precisa manter esse tema para manter também a coerência ao texto. Se houver o rompimento da manutenção temática do texto, o aluno precisa entender que a sequência lógica do texto se perderá e, portanto, a narrativização proposta por Adam (2011) também será comprometida, o que seria inadequado em um texto narrativo. A pergunta referente à consciência textual, de forma oral e escrita, também é realizada ao final dessa questão.

\subsubsection{Questão 4}

A quarta questão refere-se à organização da sequência narrativa da fábula "O leão e o rato", ou seja, à progressão temática. $\mathrm{O}$ aluno deve numerar os fatos da história em ordem cronológica. Dessa forma, à medida que o aluno numera os fatos cronologicamente, ocorre a percepção da sequenciação narrativa estabelecida na história, outro aspecto que garante a coerência textual, conforme os pressupostos de Charolles (1978). Nessa questão, a importância da narrativização de Adam (2011) fica ainda mais evidente, já que as sequências narrativas são observadas à medida que a sequência da história da fábula está sendo estabelecida. $\mathrm{Na}$ questão também é desenvolvida a metacompreensão (GUTERMAN, 2003) a partir da explicação, oral e escrita, que o aluno deve dar a respeito de como pensou para resolver a atividade.

\subsubsection{Questão 5}

A quinta questão também se refere à progressão temática textual de Charolles (1878) e, consequentemente, explora a sequência narrativa da fábula. A partir da leitura de um trecho da fábula, 0 aluno é solicitado a elaborar um novo desfecho para a narrativa. Sendo assim, o aluno precisa estar atento à progressão dos fatos para poder elaborar essa possibilidade que seja coerente com a história, dando sequência às informações já dadas pela fábula e, ao mesmo tempo, respeitando as limitações temáticas e linguísticas impostas por ela. Desse modo, para estabelecer uma nova situação final ou encerramento (ADAM, 2011), o aluno precisa levar em consideração esses aspectos. Nessa questão, o aluno também explica, oralmente e pela escrita, como pensou para realizar a atividade.

\subsubsection{Questão 6}

A sexta questão diz respeito à ausência de contradição interna textual, outra metarregra de coerência estabelecida por Charolles (1978). A partir da leitura da fábula, o aluno deve escolher a alternativa que causa contradição com o texto. As quatro alternativas se referem a um fato da história, todavia apenas uma alternativa causa contradição com a fábula. Dessa forma, o aluno precisa verificar qual é a alternativa contraditória e incoerente. Ao realizar essa verificação, o aluno também observa a sequência narrativa do texto (ADAM, 2011), para 
então identificar o que está contradizendo a sequência de fatos da história. Ao final da questão, o aluno explica, de forma oral e escrita, como pensou para realizar a atividade.

\subsubsection{Questão 7}

A sétima questão também se refere à ausência de contradição interna textual (CHAROLLES, 1978). O aluno deve escolher a alternativa que está contradizendo o desfecho da fábula. As quatro alternativas possuem alguma alteração lexical, no entanto apenas uma alternativa causa contradição com o desfecho original. O aluno precisa verificar, então, qual é o desfecho contraditório e incoerente. Ao identificar tal desfecho e descartar os demais, o aluno observa a sequência narrativa do texto (ADAM, 2011) e, então, através de suas relações de coerência, chega ao desfecho que contradiz o que a fábula apresentou até então. Ao final da questão, o aluno explica também, de maneira oral e escrita, como pensou para realizar a atividade.

\subsubsection{Questão 8}

A oitava questão refere-se à relação com 0 mundo real a partir do texto - outra metarregra de Charolles (1978). Ao ler um trecho da fábula, nota-se que foi feita uma alteração lexical. O aluno deve responder se essa alteração seria aceitável no mundo textual construído, em suas relações com o mundo real. O aluno, ao responder essa questão, deve observar, em suma, se o novo trecho é verossímil. Ao estabelecer essa relação, o aluno observa as sequências narrativas do texto (ADAM, 2011) e, ao responder à pergunta de compreensão, de forma oral e escrita, desenvolve a metacompreensão, como propõe Guterman (2003).

\subsubsection{Questão 9}

A nona e última questão também diz respeito à relação com o mundo real. Quatro trechos da fábula foram alterados lexicalmente, cabendo ao aluno escolher o trecho que não é aceitável para o mundo textual construído. O aluno, ao responder essa questão, deve observar qual o novo trecho que não é verossímil, neste caso, o leão cair em uma nuvem. Para identificá-lo, o aluno se detém à narrativização do texto, sua sequência, conforme o que Adam (2011) propõe, e se vale de mais uma metarregra para entender como se dá a coerência no texto (CHAROLLES, 1978). Ao final, o aluno explica, oralmente e de forma escrita, como pensou para realizar a atividade.

\section{Considerações finais}

Tendo este artigo a finalidade de apresentar um instrumento de verificação da consciência textual no aspecto da coerência, de alunos do $6^{\circ}$ ano do Ensino Fundamental, através do gênero fábula e do tipo textual narrativo, para embasá-lo, realizaram-se estudos teóricos sobre o tipo textual narrativo (ADAM, 2011), o gênero fábula (ROJO, 2000), a compreensão leitora, a consciência textual (GOMBERT, 1992) e a coerência textual (manutenção temática, progressão temática, ausência de contradição interna e relação com o mundo), proposta por Charolles (1878).

Como visto, um conjunto de signos que podem se mover de forma temporal e que podem operar inclusive em imagens compõem o tipo textual narrativo, sendo esse, de acordo com Adam (2011), constituído por cinco proposições essenciais. Além disso, constatou-se que o gênero fábula possui o tipo textual narrativo, sendo esse gênero trabalhado amplamente nos anos inicias do Ensino Fundamental, ocorrendo, dessa forma, um conhecimento prévio satisfatório por parte dos alunos. Decorre disso a escolha de tal gênero para compor as atividades.

O leitor, por sua vez, precisa fazer uma leitura que vá além do que está explícito, pois o implícito é essencial para a compreensão leitora. Observou-se que, ao trabalhar com os tópicos linguísticos, como por exemplo, a consciência textual com foco na coerência, há o auxílio ao aluno na interpretação de um texto específico. 
Sobre a consciência textual, constatou-se que esse tipo de consciência faz com que o leitor volte a sua atenção para o texto conscientemente, considerando diversos aspectos como, por exemplo, a coerência (que permite que o texto possua ideias conectadas). Charolles (1978) afirma que a monitoração da coerência se realiza através de quatro metarregras.

Sendo assim, através dos tópicos linguísticos explicitados anteriormente e tendo como ponto de partida o cenário educacional nacional, buscou-se fazer uma interface entre o gênero textual fábula e a consciência textual que se dá no nível da coerência. Portanto, através dessa interface, foi elaborado um instrumento de verificação que possa ser aplicado pelo professor com alunos do $6^{\circ}$ ano do Ensino Fundamental, a fim de que se verifique o nível de conhecimento dos tópicos linguísticos elucidados anteriormente, possibilitando que o professor tenha uma ferramenta que oportunize o conhecimento da situação de consciência textual de seus alunos e, possivelmente, indique caminhos para amenizar as falhas em leitura e compreensão apresentadas por eles.

\section{Referências}

ADAM, Jean Michel. Le texte narratif. 1. ed. Paris: Nathan, 1985. 243 p.

A Línguística Textual. 2. ed. São Paulo: Cortez, 2011. 368 p.

CARDOSO, Cancionila Janzkovski. Da oralidade à escrita: a produção do texto narrativo no contexto escolar. 1. ed. Cuiabá: EdUFMT, 2000.286 p.

CHAROLLES, Michel. Introduction aux problèmes de la cohérence des textes.1. ed. Paris: Langue Française $n^{\circ} 38,1978$. p. 7-42.

COHEN, Andrew D. Using verbal reports in research on language learning. In: $\mathrm{FAERCH}$, Claus; KASPER, Gabriele (Org.). Introspection in second language research. Cleverdon: Multilingual Matters, 1987. 293 p. p.82-95.

COLOMER, Teresa; CAMPS, Anna. Ensinar a ler, ensinar a compreender. Porto Alegre: Artes Médicas Sul Ltda., 2002.

DEHAENE, Stanislas. Reading in the brain. London: Penguin,
2009. $\cdot \begin{gathered}\text { Signatures of consciousness, } \\ \text { Disponível em: }\end{gathered}$ $<$ www.edge.org/.../dehaene09/dehaene09_index.h tml>. Acesso em: 13 jun. 2018

Os neurônios da leitura - como a ciência explica a nossa capacidade de ler. Porto Alegre: Penso, 2012.

FERREIRA, Sandra P. A.; DIAS, Maria G. B. B. A leitura, a produção de sentidos e o processo inferencial. Psicologia em Estudo, Maringá, v. 9, n. 3, p. 439-448, set./dez. 2004

FLÔRES, Onici Claro. Linhas e entrelinhas: leituras na sala de aula.1. ed. Santa Cruz do Sul: Edunisc, 2008. 216 p.

GOMBERT, Jean - Emile. Metalinguistic development. 1. ed. Hertfordshire: Harverster Wheatsheaf, 1992. $233 \mathrm{p}$.

GUTERMAN, Eva. Integrating written metacognitveawarencess guidance as a psychological tool to improve student performance. Learning and Instruction. Research Gate, 2003. Disponível em: $<$ https://www.researchgate.net/publication/248498 221_Integrating_written_metacognitive_awareness _guidance_as_a_'psychological_tool'_to_improve_ student_performance>. Acesso em: $0 \overline{01}$ nov. 2017

$\mathrm{KOCH}$, Ingedore Villaça \& TRAVAGLIA, Luiz Carlos. Texto e coerência. 9. ed. São Paulo: Cortez, 2003. $112 \mathrm{p}$.

LEITÃO, Márcio. Psicolinguística experimental: focalizando o processamento da linguagem. In: Martelotta, M. (org.). Manual de Linguística. 2 ed. São Paulo: Contexto, 2011, pp- 217-324.

MARCUSCHI, Luiz Antônio. Gêneros textuais: definição e funcionalidade. In: DIONíSIO, Angela Paiva; MACHADO, Anna Rachel; BEZERRA, Maria Auxiliadora (Org.). Gêneros textuais e ensino. 5. ed. Rio de Janeiro: Lucerna, 2003. 232 p. p. $20-36$

PEREIRA, Vera Wannmacher. Consciência textual nas relações entre leitura e escrita.Universidade Estadual de Maringá, 2014. Disponível em: <https://drive.google.com/file/d/0B0BzcWVyuWkV VkIBdklwQ1dTWXc/view >. Acesso em: 10 nov. 2017

PEREIRA, Vera Wannmacher; SCLIAR-CABRAL, Leonor. Compreensão de textos e consciência textual: caminhos para o ensino nos anos iniciais. Florianópolis: Insular, 2012.

ROJO, Roxane Helena Rodrigues. A prática de linguagem em sala de aula: praticando os PCN's.1. ed. São Paulo: EDUC,2001. 247 p. 
SIMON, Maria Lúcia Mexias. A construção do texto coesão e coerência textuais conceito de tópico. 2008. Disponível em: $<$ http://www.filologia.org.br/revista/40suple/a_const rucao_de_texto.pdf >. Acesso em: 13 jun. 2018.

SPINILLO, Alina Galvão; SIMÕES, Patrícia Uchoa. O desenvolvimento da consciência metatextual em crianças: questões conceituais, metodológicas e resultados de pesquisas. Psicologia: Reflexão e Crítica, v. 16, ํㅡ 3, Porto Alegre, 2003.

SPINILLO, Alina G.; MOTA, Márcia M. P. E.; CORREA, Jane. Consciência metalinguística e compreensão de leitura: diferentes facetas de uma relação complexa. Educar em revista, n. 38, p. 157-171, set/dez. 2010.

SQUIRE, Corinne. Reading narratives. Sage Journals, 2005. Disponível em: <http://journals.sagepub.com/doi/abs/10.1177/053 3316405049373 >. Acesso em: 05 nov. 2017.

TOMICH, Lêda Maria Braga. Desvelando o processo de compreensão leitora: protocolos verbais na pesquisa em leitura. Signo, v. $32, n^{\circ} 53$, p. 42-53, $2007 . \quad$ Disponível em: $<$ https://online.unisc.br/seer/index.php/signo/article /view/244/197>. Acesso em: 14 jun. 2018.

\section{COMO CITAR ESSE ARTIGO}

NEVES, Patricia de Andrade; BORGES, Caroline Bernardes. A consciência textual no gênero fábula: um instrumento de verificação da coerência com alunos do Ensino Fundamental. Signo, Santa Cruz do Sul, v. 43, n. 77, jul. 2018. ISSN 1982-2014. Disponível em: <https://online.unisc.br/seer/index.php/signo/article/view/11509>. Acesso em: doi: http://dx.doi.org/10.17058/signo.v43i77.11509. 